\title{
Patients emergency calling with traumatic dental injuries in permanent teeth
}

\author{
Adresabilitatea în urgenţă a pacienţilor cu traumatisme dento-parodontale ale \\ dinţilor permanenţi
}

\author{
Mihaela Tănase ${ }^{1}$, Aneta Munteanu', Ioana Stanciu', Daciana Zmarandache1, \\ Cătălina Farcaşiu', George Ion² \\ ${ }^{1}$ Disciplina de Pedodonţie, Facultatea de Medicină Dentară, \\ Universitatea de Medicină şi Farmacie „Carol Davila“, Bucureşti, România \\ ${ }^{2}$ Disciplina de Protetică Dentară Fixă şi Ocluzologie, Facultatea de Medicină Dentară, \\ Universitatea de Medicină şi Farmacie „Carol Davila“, Bucureşti, România
}

\begin{abstract}
The aim of the study was to assess the prevalence and distribution of traumatic dental injuries (TDI) in permanent teeth (PT) in a sample of patients who sought treatment at a pedodontic clinic.

Material and method. A retrospective descriptive study on 452 patients (212 boys) aged 8 to 16 years, who seek an emergency at the Pedodontics Department, Carol Davila University during one year. Prevalence of TDI and distribution according to age, gender, the environment origin, mean number of affected teeth/ patient, topography, type of injury and time elapsed until dental care was provided. Data were analyzed using Microsoft Excel 2010 şi SPSS 20.0 (for Windows).

Results. Prevalence of TDI was $9.7 \%$. Girls were more affected than boys ( $55 \%$ versus $45 \%$ (NS, $p>0.05$ ). Chil-dren aged 8 were the most affected. The most patients had two involved teeth $(37 \%)$, with a mean number of affected teeth/child=1.72. About $2 / 3$ of affected teeth were upper central incisors, followed by upper lateral incisors $(16 \%)$, teeth from the right side being more prevalent. Type of injuries: fractures $(64 \%)$, luxations $(27 \%)$ and mixed $(9 \%)$. Time elapsed between injury and treatment was more than 48 hours for $47 \%$ of patients and $18 \%$ of patients needed prescriptions or anti-tetanus vaccines.

Conclusions. TDI in PT is a public health problem. It is necessary to inform the people involved (parents, teach-ers, coaches, pediatricians) regarding the early attending to the pedodont of patients with TDI in order to avoid complications.
\end{abstract}

Keywords: traumatic dental injuries, permanent teeth, emergency

\section{REZUMAT}

Scopul studiului a fost evaluarea frecvenţei şi distribuţiei traumatismelor dento-parodontale (TDP) la dinţii permanenţi (DP) la un lot de pacienţi care au solicitat tratament într-o clinică de pedodonţie.

Material şi metodă. Studiul retrospectiv observaţional descriptiv, realizat pe un lot de 452 pacienţi (212 băieţi), cu vârste între 8 şi 16 ani, care s-au prezentat în urgenţă în Clinica de Pedodonţie, U.M.F "Carol Davila“, Bucureşti, într-o perioadă de un an. S-au evaluat prevalenţa şi distribuţia TDP la DP în funcţie de: vârstă, sex, mediul de provenienţă, numărul mediu DP interesaţi/pacient, topografia, tipul traumatismului şi timpul scurs până la prezentare. Datele au fost prelucrate statistic cu programele Microsoft Excel 2010 şi SPSS 20.0 (for Windows). Rezultate. Prevalenţa TDP a fost de $9,7 \%$. Fetele au fost mai afectate decât băieţii (55\% faţă de $45 \%)(N S$, $p>0,05)$. Copiii în vârstă de 8 ani au fost cel mai afectaţi. Cei mai mulţi pacienţi au avut doi dinţi afectaţi $(37 \%)$, fiind o medie $=1,72 \mathrm{DP}$ afectaţi/pacient. Aproximativ $2 / 3$ dintre dinţii afectaţi au fost incisivii centrali superiori, urmaţi de incisivii laterali superiori (16\%), predominând dinţii din hemiarcada dreaptă. Forme de traumatisme: dentare $(64 \%)$, parodontale $(27 \%)$, dento-parodontale $(9 \%) .47 \%$ dintre pacienţi s-au prezentat în clinică după mai mult de 48 ore de la producerea traumatismului şi $18 \%$ au avut nevoie de prescripţii de medicamente sau vaccin antitetanos.

Concluzii. TDP ale DP reprezintă o problemă de sănătate publică. Este necesară informarea persoanelor implicate (părinţi, profesori, antrenori, pediatri) în legătură cu prezentarea cît mai urgentă la medicul pedo-dont a pacienţilor cu TDP, pentru evitarea complicaţiilor.

Cuvinte cheie: traumatisme dento-parodontale, dinţi permanenţi, urgenţă 


\section{INTRODUCERE}

Traumatismele dento-parodontale (TDP) ale dinţilor permanenţi (DP) reprezintă o problemă de sănătate publică, din cauza consecinţelor morfofuncţionale, estetice şi psihologice. Din datele literaturii de specialitate, se consideră importante atitudinea terapeutică de urgenţă, conştientizarea pacienţilor/părinţilor privind solicitarea imediată a tratamentului, dar şi monitorizarea o perioadă lungă de timp $(1,2)$.

\section{SCOP}

Scopul studiului a fost evaluarea adresabilităţii în urgenţă a unui lot de pacienţi cu vârsta cuprinsă între 8 şi 16 ani, care au avut TDP recente la nivelul DP imaturi şi maturi şi care au solicitat tratament într-o clinică de specialitate.

\section{Material şi metodă}

Studiul retrospectiv observațional descriptiv a fost realizat pe un lot de 452 pacienţi (212 băieţi), cu vârste între 8 şi 16 ani, care s-au prezentat în urgență în Clinica de Pedodonţie, U.M.F. „Carol Davila“", Bucureşti, într-o perioadă de un an. Criteriile de includere a pacienţilor în lotul de studiu au fost: adresabilitatea în urgenţă, vârsta între 8 şi 16 ani, statusul odontal şi absenţa afecţiunilor generale asociate. Datele au fost preluate din Registrul de Urgenţă al clinicii respective, diagnosticul fiind realizat pe baza criteriilor O.M.S. modificate de Andreasen $(1,2)$.

S-au evaluat prevalenţa şi distribuţia TDP la DP în funcţie de următoarele variabile: vârstă, sex, mediul de provenienţă, numărul mediu DP interesaţi/ pacient, topografia, tipul traumatismului şi timpul scurs până la prezentare. Datele au fost prelucrate statistic cu programele Microsoft Excel 2010 şi SPSS 20.0 (for Windows). Pentru compararea rezultatelor s-au folosit testele ANOVA unifactorială şi Independent sample t-test, iar nivelul de semnificaţie a fost fixat la $\mathrm{p}=0,05$.

\section{REZULTATE}

TDP la nivelul DP imaturi şi maturi s-au întâlnit la 44 pacienţi, prevalenţa fiind de 9,7\%. Fetele au fost mai afectate decât băieţii ( $55 \%$ faţă de $45 \%)$, diferenţa fiind nesemnificativă statistic $(p>0,05)$.

Grupa de vârstă cea mai afectată a fost cea de 8 ani, aproximativ $1 / 4$ din totalul pacienţilor cu TDP la
DP, urmată de grupa de vârstă de 11 ani (1/5 din totalul pacienţilor prezentaţi) (Fig. 1).

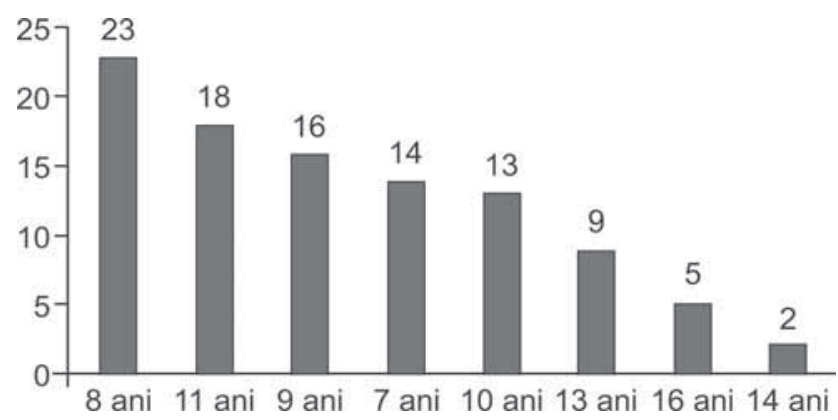

FIGURA 1. Distribuția lotului în funcție de vârstă ( $n=44$ pacienți)

Pacienţii proveniţi din mediul urban au fost mult mai afectaţi decât cei din mediul rural, diferenţa fiind semnificativă din punct de vedere statistic $(\mathrm{p}<$ 0,05) (Fig. 2).

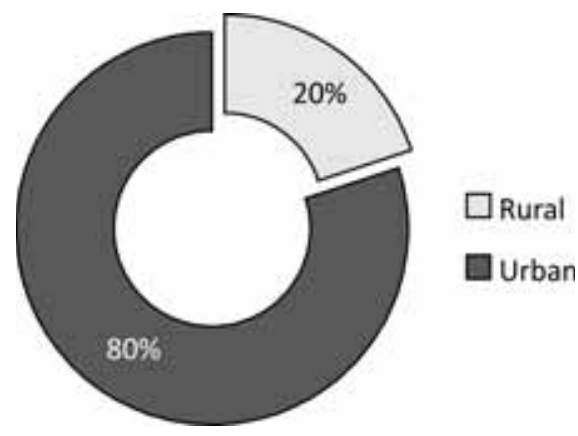

FIGURA 2. Distribuția lotului în funcție de mediul de proveniență ( $n=44$ pacienți)

Cei mai mulţi pacienţi au avut TDP la nivelul a doi dinţi (37\%), iar restul pacienţilor au avut unul sau trei dinţi cu traumatism, în proporţii aproape egale (Fig. 3).

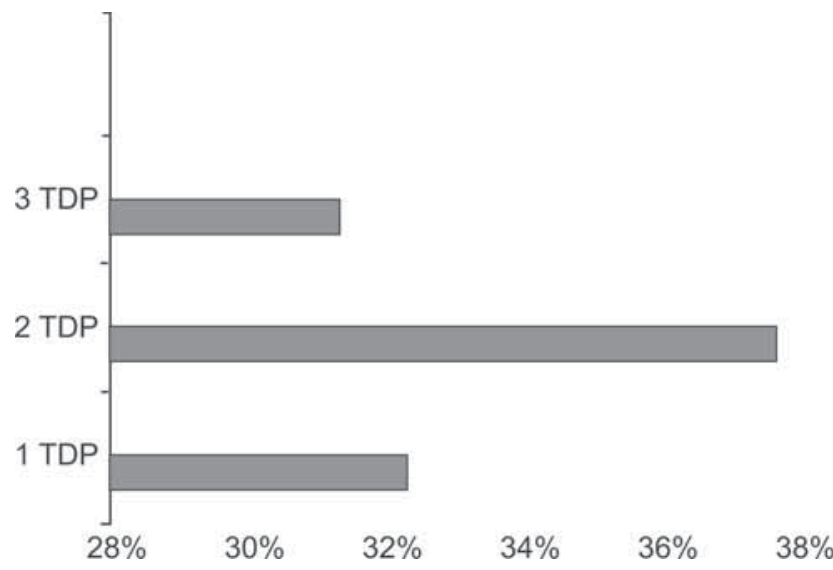

FIGURA 3. Distribuția lotului în funcție de numărul DP traumatizați $(n=44$ pacienți) 
Cei 44 de pacienţi cu TDP au avut în total 76 de dinţi afectaţi, cu o medie de 1,72 DP afectaţi/pacient.

Din totalul dinţilor traumatizaţi, aproximativ $2 / 3$ au fost incisivii centrali superiori (74\%), apoi incisivii laterali superiori $(16 \%)$, predominând dinţii din hemiarcada dreaptă, atât superior, cât şi inferior (Fig. 4).

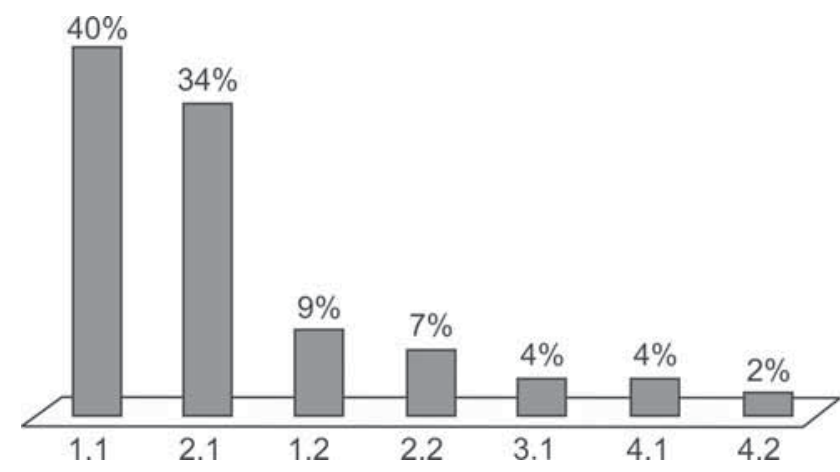

FIGURA 4. Distribuția TDP în funcție de DP implicat ( $n=76$ dinți)

Formele cele mai frecvente de traumatisme au fost traumatismele dentare, în proporţie de 64\%, urmate de traumatismele parodontale, în proporţie de $27 \%$, iar traumatismele dento-parodontale doar în proporţie de $9 \%$. De asemenea, s-a observat că cele mai multe traumatisme dentare au fost cele nepenetrante (FCN) (Fig. 5).

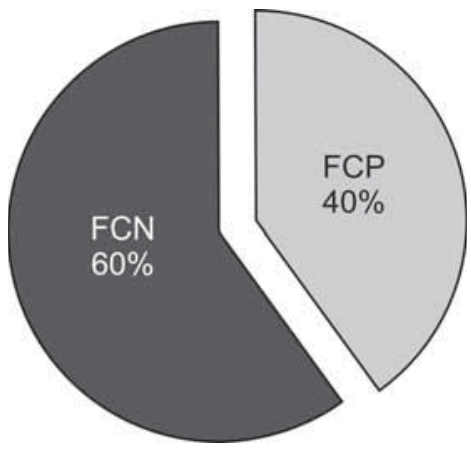

FIGURA 5. Distribuția traumatismelor dentare

Aproximativ jumătate dintre pacienţii cu TDP (47\%) s-au prezentat în clinică la un interval mare de timp (mai mult de 48 ore) de la producerea traumatismului.

De asemenea, mai puţin de $1 / 5$ dintre pacienţi $(18 \%)$ au avut nevoie de prescripţii medicamentoase (antibiotice, antiinflamatoare) sau vaccin antitetanos.

Aproape 1 din 5 pacienţi au avut şi leziuni asociate ale părţilor moi ce au necesitat îngrijire (21\%).

\section{DISCUŢII}

În literatura de specialitate se regăsesc numeroase studii ale prevalenţei, formelor clinice, tratamentului şi consecinţelor TDP ale DP imaturi şi maturi, dar sunt puţine studii despre adresabilitatea şi solicitarea consultaţiei şi tratamentului de urgenţă în această patologie frecventă la grupa de vârstă 8-16 ani.

Astfel, comparând rezultatele obţinute în studiul actual, se poate afirma că prevalența TDP ale DP de $9,7 \%$ este asemănătoare cu datele raportate în literatura internaţională. Astfel, în studii realizate în India, aceasta este de 8,79\%, iar în Turcia de 10,2\% (3, 5-7). În schimb, în Suedia, prevalenţa TDP este de $22 \%$ la aceeaşi grupă de vârstă (8-16 ani) (4).

În ceea ce priveşte vârsta la care s-au petrecut TDP, în aceste studii s-au observat că cea mai mare frecvenţă a accidentelor este cuprinsă între 8 şi 10 ani, cu un maxim la vârsta de 9 ani $(3,4,6)$. Prezentul studiu, efectuat pe un lot de populaţie pediatrică, a arătat că frecvenţa maximă a acestor traumatisme a fost la vârsta de 8 ani.

Analizându-se distribuţia pe sexe, rezultatul studiului efectuat a arătat un raport uşor mai favorabil fetelor (dar nesemnificativ statistic), în timp ce majoritatea studiilor susţin o predilecție a sexului masculin $(4,5,6)$. Acest rezultat poate fi explicat prin participarea crescută a fetelor la activităţi sportive sau recreative în aer liber.

În ceea ce priveşte forma clinică de TDP, în studiul prezent, traumatismele dentare au fost cele mai frecvente, iar dintre acestea mai mult de jumătate au fost fracturile coronare de smalţ şi dentină. De notat că diagnosticul de fisură sau fractură coronară doar la nivelul smalţului nu a fost întâlnit, posibil şi datorită faptului că pacienţii sau părinţii nu îl consideră foarte important. De asemenea, Atabek şi col. (2014) au arătat că fractura coronară de smalţ şi dentină nepenetrantă a fost cel mai des întâlnită, în 44,9\% dintre cazuri (3). Într-un alt studiu, s-a remarcat că cele mai frecvente forme au fost cele dentare, fracturile de smalţ (46,7\%) fiind cele mai numeroase, urmate de fracturile de smalţ şi dentină nepenetrante $(35,45 \%)$; doar un procent de $12,71 \%$ dintre traumatismele dentare au fost diagnosticate ca fiind penetrante (5). Alţi cercetători au susţinut că fractura coronară în smalţ a fost cel mai întâlnit tip $(80.2 \%)$, urmată de fractura coronară nepenetrantă în smalţ şi dentină (8.1\%) (7). 
Din studiul de faţă, a reieşit că cel mai afectat DP este ICS din partea dreaptă (40\%) urmat de ICS din partea stângă (34\%). Şi din alte studii de specialitate s-a observat că cel mai frecvent DP afectaţi au fost ICS (83\%), urmaţi de ILS (9,05\%) şi ICI $(6,9 \%)(5)$. Altă cercetare a arătat tot că ICS au fost cei mai traumatizaţi $(66,24 \%)$ (3). Dintr-un studiu realizat în Suedia, tot ICS au fost afectaţi de traumatisme dento-parodontale (4). Un alt studiu din India susţine, de asemenea, că ICS au fost traumatizaţi într-o proporţie mare $(81,4 \%)$, urmati de ILS $(10,5 \%)$, de ICI $(5,8 \%)$ şi de ILI $(1,2 \%)(7)$.

În ceea ce priveşte timpul scurs de la producerea accidentului până la prezentare la medic, puţine studii au notat acest lucru.

\section{CONCLUZII}

TDP ale DP reprezintă una dintre cele mai grave probleme de sănătate publică în medicina dentară, afectând $\mathbf{8 , 7 9 - 2 2 \%}$ din populaţia pediatrică. Impli-

\section{BIBLIOGRAFIE}

1. Andersson L, Andreasen JO, Day P, Heithersay G, Trope M, Diangelis AJ. International Association of Dental Traumatology guidelines for the management of traumatic dental injuries: 2. Avulsion of permanent teeth. Dent Traumatol. 2012; 28: 88-96.

2. Luca R. Pedodonţie, Vol. 3. Editura Cermaprint, Bucureşti, 2013: 5-60.

3. Atabek D, Alaçam A, Aydintuğ I, Konakoğlu G. A retrospective study of traumatic dental injuries. Dent Traumatol 2014, 30 (2): 154-161.

4. Borssén E, Holm AK. Treatment of traumatic dental injuries in a cohort of 16-year-olds in northern Sweden. Dent Traumatol 2000, 16: 276-281. caţiile imediate şi consecinţele pe termen lung ale acestei patologii sunt adeseori dramatice pentru pacient, din perspectiva impactului fizic, psihic şi social. Timpul scurs de la producerea traumatismului şi până la prezentarea la medic reprezintă un factor esenţial în „salvarea“ dintelui interesat, relevând necesitatea informării persoanelor implicate (părinţi, profesori, antrenori, pediatri) despre importanţa prezentării la medic, chiar dacă traumatismul pare minor.

Medicului specialist pedodont îi revine datoria de a acorda tratamentul de urgenţă adecvat şi rapid, deoarece abordarea corectă în primele ore după producerea accidentului poate determina păstrarea optimă a unui DP traumatizat.

Notă: Autorii au contribuit în mod egal la prezentul articol, de aceea toți sunt considerați autori principali.

Conflict of interest: none declared Financial support: none declared

5. Patel MC, Sujan SG. The prevalence of traumatic dental injuries to permanent anterior teeth and its relation with predisposing risk factors among 8-13 years school children of Vadodara city: An epidemiological study. J Indian Soc Pedod Prev Dent 2012; 30: 151-7

6. Sandalli N, Cildir S, Guler N. Clinical investigation of traumatic injuries in Yeditepe University, Turkey during the last 3 years. Dent Traumatol 2005, 21: 188-194.

7. Chopra A, Lakhanpal M, Rao NC, Gupta N, Vashisth S. Traumatic Dental Injuries Among 12-15-Year-Old-School Children in Panchkula. Arch Trauma Res 2014; 3(1): e18127. 